\title{
Student reading behaviors and preferences at public and private universities in Ecuador: A comparative study
}

\author{
Hubert B. Van Hoof ${ }^{1}$, Amit Sharma ${ }^{1}$, Joonho Moon ${ }^{1}$, Miguel Angel Galarza Cordero ${ }^{2}$, Karina \\ Farfán Pacheco ${ }^{3}$ \\ ${ }^{1}$ School of Hospitality Management, Penn State University, Pennsylvania, USA. \\ ${ }^{2}$ Facultad de Ciencias de la Hospitalidad, Universidad de Cuenca, Cuenca, Ecuador. \\ ${ }^{3}$ Facultad de Filosofía, Letras y Ciencias de la Educación, Universidad del Azuay, Cuenca, Ecuador. \\ Autor para correspondencia: hbv1@psu.edu \\ Fecha de recepción: 22 de febrero 2013 - Fecha de aceptación: 15 de mayo 2013
}

\begin{abstract}
Reading compliance is reading assigned course materials in preparation for class. Previous research in university settings in the US suggests that compliance with a professor's request to prepare for class among undergraduate students is low. This paper reports on a study conducted among undergraduate students at the Universities of Cuenca and Azuay in Cuenca, Ecuador to assess their reading behaviors and preferences as well as the factors that influence their decisions to comply or not comply with their professors' assigned course readings. The study found that, whereas students are generally positive about the value of their reading assignments, they do not read much. Considerable differences of opinion exist between public and private university students on the topic. The study advocates a more active role for professors in enhancing students reading behaviors and suggests opportunities for future research.
\end{abstract}

Keywords: Reading compliance, reading behavior, comparative analysis, University of Cuenca, University of Azuay.

\section{RESUMEN}

El cumplimiento de lectura es el proceso de leer los materiales del curso asignados, para la preparación de la clase. Investigaciones previas en entornos universitarios en los Estados Unidos, sugieren que el cumplimiento de la petición de un profesor para preparar la clase entre los estudiantes universitarios es bajo. Este documento informa sobre un estudio realizado entre los estudiantes de pregrado en las universidades de Cuenca y Azuay, en la ciudad de Cuenca, Ecuador; con el fin de evaluar sus comportamientos y preferencias de lectura. Así también, los factores que influyen en sus decisiones para cumplir o no cumplir con las lecturas del curso asignadas por sus profesores. El estudio encontró que, mientras los estudiantes son positivos sobre el valor de sus tareas de lectura en general, no leen mucho. Existen considerables diferencias de opinión entre los estudiantes universitarios públicos y privados sobre el tema. El estudio aboga por un papel más activo de los profesores en mejorar los comportamientos de lectura de los estudiantes y sugiere oportunidades para futuras investigaciones.

Palabras clave: El cumplimiento de lectura, conducta de la lectura, el análisis comparativo, Universidad de Cuenca, Universidad del Azuay.

\section{INTRODUCTION}

The term "reading compliance" refers to the process of reading course assigned materials such as a book chapter, an article, or a Web page in preparation of class. Instructors assign readings prior to class to make students read the topics to be discussed in class under the assumption that their class presentations can build upon knowledge the students have obtained through the readings and thereby 
enhance the learning process and its outcomes. The assumptions behind asking students to read in preparation of class are relatively simple: if students read before class, the instructor can use scarce class time to expand upon the knowledge obtained through the readings and introduce new and perhaps higher level material in class. Readings can be used for targeted class discussion and to reinforce class presentations with written information. When students are presented with information several times and in different formats their comprehension of the material will grow and class discussion will be richer. Yet, those assumptions would only hold true if students actually read the material they are assigned, or in other words, if they comply.

Past research suggests that reading compliance amongst undergraduate students is low and that non-compliance negatively affects student performance (Hobson, 2004). This lack of reading compliance, which is especially prominent among undergraduate students, is of significant concern to college and university instructors worldwide (Baier et al., 2011) and anecdotal evidence suggests that non-compliance is growing among present student generations.

Preparing for class by reading course materials is one of the tasks that students are asked to perform as they take part in a course. It is a task that, in essence, requires the student to make a conscious decision whether or not to read his/her assigned course materials. At first glance, this may appear to be an easy decision, however students ought to understand the relationship between reading course materials and their ability to obtain a good course grade. The more they read, the better prepared they are for class and for their tests. Reading course materials helps them accomplish the objective of getting a better grade. It is not the only task they have to accomplish during their college careers, yet it is an important one. The reality, however, is that students are faced with several options on how to spend their limited time and they often spend it in ways that their instructors might not endorse. They can spend their time reading and preparing for class, yet they can also spend it on other academic activities, on non-academic or social activities, or on working to cover their expenses, just to name a few. So students are faced with numerous choices: choices about how involved they are in their own education, about what classes to attend and participate and on how to allocate time between competing activities of varying importance and urgency.

Reading course assignments takes time and competes with other activities for their attention, which makes it a more complex decision than it appears to be. It is not just a matter of "reading or not reading," but also a matter of "reading instead of socializing," "reading instead of working," or "reading instead of playing soccer or sleeping in." As Fujita et al. (2006) found individuals' ability to make complex decisions of resource allocation (such as time) about activities that do not necessarily result in immediate benefits is limited and individuals have been shown to be inefficient in the rationing of scarce resources such as time (Wertenbroch, 2002). In the case of reading a chapter or article before class, its effect on a course grade might not be immediately apparent to a student, which makes the decision to read and comply with the professor's request more complex.

The purpose of the study reported here was to investigate and compare the reading and reading compliance behaviors of undergraduate students at the University of Cuenca and the University of Azuay and to assess the factors that influence their decision making processes. Knowledge about student reading behaviors, such as how much time they spend on their readings, when, where and how they read, as well as understanding the factors that influence their reading behavior can help instructors in adjusting their expectations of student reading compliance. The results can also be of value for professors and administrators as they look for ways to intervene effectively in the process and modify how, what and when they ask their students to read.

\section{Reading Compliance in Higher Education: A Review of Recent Literature}

Reading compliance in higher education has been a popular topic in the literature and scholars from many different disciplines, with a preponderance of the psychology field, have investigated the phenomenon and discussed the effectiveness of various methods of stimulating reading compliance among college students. In order to present the most current information, this article only reports on the literature on the topic since 2000 and will discuss some of the tools that have been investigated and developed over time to stimulate reading compliance. 
In their study of reading compliance in psychology courses from introductory to graduate levels between 1981 and 1997, Burchfield and Sappington (2000) found that reading compliance had declined over the years. Yet, they also determined that older students tended to comply better than younger students and graduate-level students complied better than undergraduates. They recommended that professors should try to stimulate reading compliance by using unannounced, surprise quizzes. This idea of using continuous and, sometimes surprise, reinforcement by means of quizzes/tests was supported by Connor-Greene (2000), who found that only $16 \%$ of the students she investigated read before class when the instructor used regularly scheduled exams. However, when the instructor used daily essays to verify reading compliance almost all (92\%) of the students in the study indicated that they had read their assignments prior to class.

A pair of studies reported by Sappington et al. (2002) also found that college students tended to resist required class readings. Yet, more importantly perhaps, they also determined that instructors were not keen on testing students on their reading assignments for fear of student disapproval and how that would be reflected on their faculty evaluations. Their first study found that relying on students to self-report on their reading compliance was invalid because students tended to distort the facts. The second study demonstrated the utility of using an initial surprise quiz to test reading compliance but also to use that quiz to predict scores on final exams. The article suggested that instructors might want to consider using surprise quizzes, despite the fact that they might not want to use them for fear of student reprisal. The authors furthermore suggested that instructors could use the quiz results to illustrate the benefits of reading compliance to students and to emphasize to the students' their responsibilities in enhancing the learning process and its outcomes.

Kouyoumdjian (2004) also focused on surprise quizzes as a means to stimulate reading compliance. He compared the influence of infrequent and minimal-weight unannounced quizzes to a cumulative exam on students' self-reported motivation to attend class and to keep up with class reading assignments. The results of the study again showed that unannounced quizzes had more influence on self-reported motivation to attend class and study regularly than a cumulative exam. Student respondents felt that these quizzes were helpful as motivational tools to attend and prepare for class and rated them positively.

As the various studies reviewed so far have shown, the use of short announced or unannounced quizzes, as opposed to regular exams that are announced far ahead of time, appears to have an overall positive effect on stimulating reading compliance. Several other studies suggest additional stimuli and present further information on the topic. In one study (Clump et al., 2004) 27\% of students surveyed reported completing the assigned reading before each class while $70 \%$ of them in the study postponed the reading assignments until it was time for them to take an exam. Clump and Doll (2007) later corroborated those findings: most students prefer to read assignments right before their exams rather than trying to keep up with their regularly scheduled reading assignments during the course of the semester.

Besides surprise quizzes or writing assignments to verify reading compliance, other techniques exist that have been investigated and applied to increase reading compliance among college students. Uskul and Eaton (2005) assigned their students in a psychology class long-answer questions rather than short-answer multiple choice questions in their hope to increase reading compliance among their students. They evaluated the effectiveness of this technique by analyzing both the exam scores and the student evaluations and they found that students had performed significantly better on the exam questions that were related to the topics covered by the long-answer questions than they did on the short-answer multiple choice questions related to other topics. Of interest was not only the fact that students reported having read significantly more of the assigned material when long-answer essay questions were assigned but also that they evaluated this testing method positively and that they recommended it for use in future classes.

A study conducted by Johnson and Kiviniemi (2009) investigated the detrimental effect of students not completing reading assignments, or only completing them immediately before an exam on both their learning and their overall course performances. They examined the effectiveness of compulsory, mastery-based, weekly reading quizzes as a means of improving exam and course performance and found that completion of reading quizzes was related to both better exam scores and an improved overall course performance. 
At the graduate student level, McMinn et al. (2009) surveyed 744 students enrolled in doctoral programs accredited by the American Psychological Association. They found that the reported amount of assigned readings varied widely among graduate schools. The graduate level respondents reported that they only completed about half the assigned readings thoroughly. Yet, on the positive side, thorough or detailed reading of assigned materials was more common than just skimming or not reading them at all.

Lineweaver (2010) developed a different tool to stimulate reading compliance. He developed an online discussion assignment as a required component of a cognitive psychology course in order to increase the number of students reading the text before class and to promote student interaction about text material. The author found that this assignment had a limited effect on examination performance but also found that those students who had completed the online discussions were more likely to have read the textbook and the reading prior to class. Respondents stated that they had read assigned materials more carefully and indicated that they had understood the lectures better and that they felt more prepared for exams. These results supported previous studies that had suggested that online discussions could also be an effective tool to enhance reading compliance.

Yet another tool that was developed to stimulate students to read before class was the Textbook Assessment and Usage Scale (TAUS) (Gurung and Martin, 2010). They used this instrument to measure students' textbook evaluations and reading behaviors and found that student gender, student perceptions of the quality of visuals, pedagogical aids, photographs, writing, and course design all predicted student text reading behaviors and exam scores.

Besides surprise quizzes, long-answer test questions and online discussion forums other motivators and circumstances affecting student reading behaviors have also been investigated. Lei et al. (2010) found that college students were inclined not to read because of low self-confidence, a disinterest in the subject matter or because they underestimated the importance of the required reading assignments. College instructors were found unmotivated to reinforce student reading for fear of poor student evaluations.

Marek and Christopher (2011) took another approach and looked at the importance of the textbook. In several psychology courses they surveyed 311 students by means of an online survey. In the survey the students answered questions about textbook importance, usage, and preferences and about scenarios that described a textbook as a resource or central course element. This study found that, if an instructor expected students to read and understand textbook material before class, the students perceived that they would learn less, enjoy the course less and that they considered the course to be more difficult than if an instructor has prescribed the textbook merely as a resource to which students might refer for clarification.

Finally, Coulter and Smith (2012) assessed the value of mandatory pre-class readings (PCRs) and pre-class quizzes (PCQs) in a physical therapy course by correlating performance on PCQs to examination performance and then evaluated student satisfaction of these assessments via a class survey. They found a positive correlation between student PCQs and examination grades. The results of the student survey showed that student satisfaction with these techniques enhanced reading compliance and students considered both PCRs and PCQs to be beneficial and helpful in their efforts to read before class.

\section{METHODOLOGY AND DATA COLLECTION}

\subsection{The instrument}

As the previous review of recent literature has suggested, reading compliance is declining and reading behaviors in higher education are deteriorating.These tendencies are of growing concern to educators. In an effort to determine how students in a South American setting read in preparation for classes, whether the reading behaviors of students in a public and a private university were significantly different, what factors influenced their decision making processes and what interventions might be appropriate to stimulate reading compliance behavior from the students' perspectives, this study used a 
survey to investigate the various issues among students in a private university (University of Azuay) and a public university (University of Cuenca) in Cuenca, Ecuador. The survey was a duplication of an instrument that was designed for similar purposes by the researchers at Penn State University in the United States. The existing survey was translated from English to Spanish and then back to English by two English language faculty members in the university to verify the accuracy of the Spanish language instrument. It was slightly adjusted to match the local university environment.

After translation and modification, the survey was presented to a pilot group of six undergraduate students at the University of Cuenca. Based on their comments several small modifications were made that enhanced the clarity of some of the questions. The pilot group determined that the survey would take approximately 10-15 minutes to complete. In an accompanying statement to the survey, respondents were encouraged to answer all questions carefully and honestly and were assured of the confidentiality of the process and their right of refusal to participate. Contact information about the investigators was included in this statement. In order to achieve the highest possible response rate and the widest variability of responses, it was decided to use a hard copy format of the survey rather than a web-based format, as previous research has found that web-based surveys tend to suffer from low response rates (Tse, 1998; Schaefer and Dillman, 1998).

The survey was five pages in length, self-administered and divided into three parts:

- Part A, entitled "Preferencias para Leer" (Reading Preferences) asked students to provide information about how much time they spent on class-related and on other reading materials and when they completed their reading assignments, and asked for their opinions about why they did not complete their reading assignments and how they could be stimulated to complete them. Topics were presented in the form of brief statements to which the respondent had to chose his/her level of agreement.

- Part B entitled "Las Lecturas" (The Readings) focused on student perceptions about their readings, the priorities they attached to their readings, when they generally completed readings for classes and exams, what could be done to stimulate them to read, and how the university could help them complete their reading assignments.

- Part $\mathrm{C}$ of the survey was dedicated to obtaining relevant demographic information about the respondents. The survey asked respondents to share their gender and age.

\subsection{Data collection and limitations}

Prior to conducting the survey, the researchers asked the Rectors of both universities in person and in writing to support the project and to announce its intent to the deans of the various colleges during a regular meeting of their university councils. Assured of the support of the Rectors and the approval of the deans, the investigators then approached colleagues in classes in a variety of faculties (colleges) in both universities with the request to administer the survey in their classes.

The survey was conducted between the 5th and 22nd of December, 2012. Since the investigators hoped to achieve the highest possible response rate and as they were dependent on the willingness of professors in various faculties to support the effort in their classes, the sampling procedures were not random. On December 22, the end of the data collection period, a total of 371 completed surveys was collected at the University of Cuenca and 487 completed surveys were collected at the University of Azuay.

The main limitation of this study was that, since it was administered to students at only two universities, the results say more about the reading behaviors and perceptions of students in Cuenca than about students at other universities in Ecuador. Combined with the earlier stated fact that respondent selection was not random, its results cannot be generalized beyond the scope of the study. Furthermore, the surveys were self-reported and the researchers had to trust that respondents felt comfortable enough about the guaranteed confidentiality that they answered the questions truthfully. Not all faculties were included in the study. However, the results may be considered suggestive of broader tendencies and reading behaviors in higher education in the country.

This paper will first discuss the demographic data and the most important descriptive results of the analyses as summarized in a number of tables. After that it will discuss the outcomes of the various comparative analyses that were performed to determine if any of the observed differences in the 
descriptive data between the various groups of respondents (public vs. private, male vs. female, older vs. younger students) were significant. Finally, it will summarize the dominant issues, suggest possible interventions to improve reading behaviors and offer suggestions for future research.

\section{DESCRIPTIVE RESULTS}

\subsection{Respondent demographics}

As Table 1 shows, there were 487 respondents from the University of Azuay (UDA) (56,9\%) and 371 $(43,1 \%)$ respondents from the University of Cuenca (UC), a total of 858 respondents. Reflective of overall enrollments at both universities, a majority of the respondents was female (614 or 71,7\%). The age distribution in the sample was virtually even: 434 students were 20 years old or younger $(49,4 \%)$ with the remainder $(50,6 \%)$ being over the age of 20 (see Table 1).

\subsection{Reading preferences}

The first part of the survey entitled "Preferencias para Leer" asked respondents to provide information about how much time they spent on their reading assignments, how often they completed their reading assignments, what their opinions were about various aspects of their reading assignments, why they did not complete their reading assignments and how they could be stimulated to complete them.

The study found that students spent an average of 5,9 hours during the week on reading their class assignments. UC students reported reading an average of 7,5 hours, with the students at UDA reading an average of 4,6 hours per work week. When asked to respond to the statement "I complete reading my course assignments," a large majority reported they completed them "most of the time" $(62,4 \%)$ or "always" (16,1\%), with 19,3\% selecting "rarely" and 2,2\% stating they "never" completed their assignments. Broken down by university, the responses were virtually identical, with students at UC selecting "most of the time" more often and students at UDA favoring "always" somewhat (see Table 2).

A third group of statements in this section described various aspects of student reading assignments and the respondents were asked to express their level of agreement with each statement (1 $=$ strongly disagree, $2=$ disagree, $3=$ agree and $4=$ strongly agree). As Table 2 shows, students were not overly burdened by their reading assignments, although small majorities felt that they had too many assignments and that their assignments were too long. This opinion was more prominent among students at the University of Cuenca, who had already stated earlier that they read more than their counterparts at the University of Azuay. The respondents were quite positive about the nature of their assignments, with only small variations between the groups: respondents agreed that their assignments were interesting and up-to-date, that they were easy to understand and enjoyable to read (see Table 2).

The fourth section asked students why they did not finish their reading assignments. This was done by means of a series of seven statements. In this case, the scales were $1=$ always, $2=$ mostly, $3=$ sometimes and $4=$ never. As Table 3 suggests, there were some differences of opinion between the two groups. Students at UDA felt their reading assignments to be less time consuming and also had more time to read than their peers at UC. Those results could be reflective of earlier data in which UC students indicated they read considerably more per week than their UDA peers. Another interesting difference between the two groups was that UC students were much more outspoken about their books being too expensive as opposed to UDA students (see Table 3 ).

The final section of this part of the survey looked at conditions under which students were more likely to finish their assignments. Participants were presented with five statements to agree with, so scales were $1=$ strongly disagree, $2=$ disagree, $3=$ agree and $4=$ strongly agree. As Table 4 shows, students were more likely to finish their assignments if their assignments were graded $(79,4 \%$ agreed or strongly agreed), if they received a lower grade for not reading (77\% agreed), if they were tested on the readings (85,2\% agreed) or if they might be called upon in class ( $86 \%$ agreed) (see Table 4$)$. These were mostly negative reinforcements, yet reinforcements nevertheless and well within the control of the professor. 
Table 1. Student demographics $(\mathrm{N}=858)$.

\begin{tabular}{ccc}
\hline University & $N$ & Valid \% \\
\hline University of Azuay & 487 & $56,8 \%$ \\
University of Cuenca & 371 & $43,2 \%$ \\
\hline Gender & $N$ & Valid \% \\
\hline Female & 614 & $71,7 \%$ \\
Male & 242 & $28,3 \%$ \\
\hline Age & $N$ & Valid \% \\
\hline <=20 years of age & 434 & $50,6 \%$ \\
$>20$ years of age & 424 & $49,4 \%$ \\
\hline
\end{tabular}

Table 2: Student reading behaviors and preferences.

\begin{tabular}{lrrr}
\hline Completion of assignments & UC & \multicolumn{1}{c}{ UDA } & Overall \\
\hline Never & $2,4 \%$ & $2,1 \%$ & $2,2 \%$ \\
Rarely & $17,5 \%$ & $20,7 \%$ & $21,6 \%$ \\
Most of the time & $68,2 \%$ & $57,9 \%$ & $62,4 \%$ \\
Always & $11,9 \%$ & $19,3 \%$ & $16,1 \%$ \\
\hline I get too many assignments & UC & UDA & Overall \\
\hline Strongly disagree & $5,9 \%$ & $12,3 \%$ & $9,6 \%$ \\
Disagree & $22,4 \%$ & $38,6 \%$ & $31,6 \%$ \\
Agree & $56,3 \%$ & $42,5 \%$ & $48,5 \%$ \\
Strongly agree & $15,4 \%$ & $6,6 \%$ & $10,4 \%$ \\
\hline My assignments are too long & $U C$ & $U D A$ & Overall \\
\hline Strongly disagree & $5,4 \%$ & $10,7 \%$ & $8,4 \%$ \\
Disagree & $27,2 \%$ & $48,0 \%$ & $39,0 \%$ \\
Agree & $50,1 \%$ & $33,9 \%$ & $40,9 \%$ \\
Strongly agree & $17,3 \%$ & $7,2 \%$ & $11,5 \%$ \\
\hline My assignments are not interesting & $U C$ & $U D A$ & Overall \\
\hline Strongly disagree & $18,6 \%$ & $20,7 \%$ & $19,8 \%$ \\
Disagree & $55,0 \%$ & $52,0 \%$ & $53,3 \%$ \\
Agree & $19,1 \%$ & $22,2 \%$ & $20,9 \%$ \\
Strongly agree & $7,3 \%$ & $5,1 \%$ & $6,1 \%$ \\
\hline My assignments are up-to-date & UC & UDA & Overall \\
\hline Strongly disagree & $5,7 \%$ & $6,4 \%$ & $6,1 \%$ \\
Disagree & $16,7 \%$ & $15,4 \%$ & $16,0 \%$ \\
Agree & $58,8 \%$ & $55,2 \%$ & $56,8 \%$ \\
Strongly agree & $18,9 \%$ & $23,0 \%$ & $21,2 \%$ \\
\hline My assignments are easy to & UC & UDA & Overall \\
\hline Strongly disagree & $3,8 \%$ & $7,6 \%$ & $5,9 \%$ \\
Disagree & $43,1 \%$ & $27,9 \%$ & $32,9 \%$ \\
Agree & $50,4 \%$ & $54,2 \%$ & $52,6 \%$ \\
Strongly agree & $6,5 \%$ & $10,3 \%$ & $8,6 \%$ \\
\hline My assignments are enjoyable to & UC & UDA & Overall \\
\hline Strongly disagree & $4,3 \%$ & $5,5 \%$ & $5,0 \%$ \\
Disagree & $21,6 \%$ & $22,6 \%$ & $22,1 \%$ \\
Agree & $64,2 \%$ & $58,9 \%$ & $61,2 \%$ \\
Strongly agree & $10,0 \%$ & $12,9 \%$ & $11,7 \%$ \\
\hline & & & \\
& & & \\
& & &
\end{tabular}

\subsection{Reading assignments}

The second section of the survey entitled "Las Lecturas" (The Readings) focused on student perceptions about their readings, the priorities they attached to their readings, when they generally completed readings for classes and exams, what could be done to stimulate them to read and how the university could help them complete their reading assignments. Statements used similar four-point scales as described above.

As Table 5 shows, students were aware of the value of their reading assignments to their studies: not only did they agree that completing their assignments helped them get better grades and in class discussions, but also that they were helpful in understanding course content better. They were also positive about their impact on their future lives and careers and even felt they helped them become a better person (see Table 5). In a final statement in this section, respondents reacted to the statement "I really do not see the benefits of completing my reading assignments." More than 70 percent $(70,4 \%)$ of the respondents disagreed with the statement, indicating that most students are aware of the value 
MASKANA, Vol. 4, No. 1, 2013

Table 3. Reasons why students do Not Finish their reading assignments.

\begin{tabular}{lrrr}
\hline Assignments are tedious to complete & UC & UDA & Overall \\
\hline Always & $5,7 \%$ & $7,6 \%$ & $6,8 \%$ \\
Mostly & $28,8 \%$ & $21,6 \%$ & $24,7 \%$ \\
Sometimes & $62,3 \%$ & $63,9 \%$ & $63,2 \%$ \\
Never & $3,3 \%$ & $7,0 \%$ & $5,3 \%$ \\
\hline Assignments take a lot of time & UC & UDA & Overall \\
\hline Always & $14,6 \%$ & $7,4 \%$ & $10,5 \%$ \\
Mostly & $43,7 \%$ & $28,7 \%$ & $35,7 \%$ \\
Sometimes & $39,4 \%$ & $55,9 \%$ & $48,7 \%$ \\
Never & $2,4 \%$ & $8,0 \%$ & $5,6 \%$ \\
\hline I do not have enough time & $U C$ & $U D A$ & Overall \\
\hline Always & $10,5 \%$ & $11,7 \%$ & $11,2 \%$ \\
Mostly & $30,2 \%$ & $17,0 \%$ & $22,7 \%$ \\
Sometimes & $54,2 \%$ & $53,2 \%$ & $53,6 \%$ \\
Never & $5,1 \%$ & $18,1 \%$ & $12,5 \%$ \\
\hline Assignments not discussed in class & $U C$ & $U D A$ & Overall \\
\hline Always & $7,5 \%$ & $17,5 \%$ & $13,2 \%$ \\
Mostly & $20,2 \%$ & $16,2 \%$ & $17,9 \%$ \\
Sometimes & $51,8 \%$ & $39,6 \%$ & $44,9 \%$ \\
Never & $20,5 \%$ & $26,7 \%$ & $24,0 \%$ \\
\hline My tests not based on assignments & $U C$ & $U D A$ & Overall \\
\hline Always & $7,5 \%$ & $14,8 \%$ & $12,2 \%$ \\
Mostly & $20,2 \%$ & $12,3 \%$ & $13,8 \%$ \\
Sometimes & $51,8 \%$ & $36,6 \%$ & $41,6 \%$ \\
Never & $20,5 \%$ & $36,3 \%$ & $32,4 \%$ \\
\hline Books are too expensive to buy & UC & UDA & Overall \\
\hline Always & $18,6 \%$ & $11,3 \%$ & $14,5 \%$ \\
Mostly & $18,9 \%$ & $12,9 \%$ & $15,5 \%$ \\
Sometimes & $37,7 \%$ & $34,1 \%$ & $35,7 \%$ \\
Never & $24,8 \%$ & $41,6 \%$ & $34,4 \%$ \\
\hline My professor covers assignments in & UC & UDA & Overall \\
class so I do not read them & $13,5 \%$ & $10,3 \%$ & $11,7 \%$ \\
\hline Always & $17,3 \%$ & $18,9 \%$ & $18,2 \%$ \\
Mostly & $54,4 \%$ & $53,8 \%$ & $54,1 \%$ \\
Sometimes & $14,8 \%$ & $17,0 \%$ & $16,1 \%$ \\
\hline Never & & & \\
\hline & & & \\
& & &
\end{tabular}

Table 4. Reasons why students are More Likely to Finish their reading assignments.

\begin{tabular}{lrrr}
\hline Reading assignments are graded & UC & UDA & Overall \\
\hline Strongly disagree & $7,3 \%$ & $10,5 \%$ & $9,1 \%$ \\
Disagree & $9,7 \%$ & $12,9 \%$ & $11,5 \%$ \\
Agree & $45,8 \%$ & $46,8 \%$ & $46,4 \%$ \\
Strongly agree & $37,2 \%$ & $29,8 \%$ & $33,0 \%$ \\
\hline I receive a lower grade if I do not read & UC & UD & Overall \\
\hline Strongly disagree & $7,8 \%$ & $8,8 \%$ & $8,4 \%$ \\
Disagree & $13,5 \%$ & $15,4 \%$ & $14,6 \%$ \\
Agree & $49,6 \%$ & $45,6 \%$ & $47,3 \%$ \\
Strongly agree & $29,1 \%$ & $30,2 \%$ & $29,7 \%$ \\
\hline Quizzes and Exams on Readings & $U C$ & $U D A$ & Overall \\
\hline Strongly disagree & $4,3 \%$ & $8,0 \%$ & $6,4 \%$ \\
Disagree & $7,5 \%$ & $9,0 \%$ & $8,4 \%$ \\
Agree & $55,0 \%$ & $50,5 \%$ & $52,4 \%$ \\
Strongly agree & $33,1 \%$ & $32,4 \%$ & $32,8 \%$ \\
\hline I might be called upon in class & $U C$ & $U D A$ & Overall \\
\hline Strongly disagree & $4,9 \%$ & $8,2 \%$ & $6,8 \%$ \\
Disagree & $7,0 \%$ & $15,6 \%$ & $7,2 \%$ \\
Agree & $59,6 \%$ & $52,6 \%$ & $55,6 \%$ \\
Strongly agree & $28,6 \%$ & $31,8 \%$ & $30,4 \%$ \\
\hline No notes/slides in class about readings & $U C$ & $U D A$ & Overall \\
\hline Strongly disagree & $12,1 \%$ & $15,2 \%$ & $13,9 \%$ \\
Disagree & $37,7 \%$ & $34,5 \%$ & $35,9 \%$ \\
Agree & $39,9 \%$ & $35,7 \%$ & $37,5 \%$ \\
Strongly agree & $10,2 \%$ & $14,6 \%$ & $12,7 \%$ \\
\hline
\end{tabular}

\section{Revista semestral de la DIUC}


and importance of their reading assignments. The study furthermore found that students tended to read their assignments either on the day of class or on the day before class, yet not long before class. Similar behaviors were reported with regard to reading assignments for exams.

Table 5. Student opinions about their reading assignments.

\begin{tabular}{|c|c|c|c|}
\hline Assignments help me get better grade & $U C$ & $U D A$ & Overall \\
\hline Strongly disagree & $7,3 \%$ & $6,4 \%$ & $6,8 \%$ \\
\hline Disagree & $9,7 \%$ & $7,8 \%$ & $8,6 \%$ \\
\hline Agree & $45,8 \%$ & $50,9 \%$ & $48,7 \%$ \\
\hline Strongly agree & $37,2 \%$ & $34,9 \%$ & $35,9 \%$ \\
\hline $\begin{array}{l}\text { Assignments present different } \\
\text { perspective than my professor }\end{array}$ & $U C$ & $U D A$ & Overall \\
\hline Strongly disagree & $7,8 \%$ & $7,0 \%$ & $7,3 \%$ \\
\hline Disagree & $13,5 \%$ & $22,8 \%$ & $18,8 \%$ \\
\hline Agree & $49,6 \%$ & $52,0 \%$ & $50,9 \%$ \\
\hline Strongly agree & $29,1 \%$ & $18,3 \%$ & $23,0 \%$ \\
\hline $\begin{array}{l}\text { Assignment help me participate in } \\
\text { classroom discussions }\end{array}$ & $U C$ & $U D A$ & Overall \\
\hline Strongly disagree & $4,3 \%$ & $4,5 \%$ & $4,4 \%$ \\
\hline Disagree & $7,5 \%$ & $9,7 \%$ & $8,7 \%$ \\
\hline Agree & $55,0 \%$ & $54,0 \%$ & $54,4 \%$ \\
\hline Strongly agree & $33,2 \%$ & $31,8 \%$ & $32,4 \%$ \\
\hline $\begin{array}{l}\text { Assignments help me understand } \\
\text { course content better }\end{array}$ & $U C$ & $U D A$ & Overall \\
\hline Strongly disagree & $4,9 \%$ & $5,5 \%$ & $5,2 \%$ \\
\hline Disagree & $7,0 \%$ & $7,8 \%$ & $7,5 \%$ \\
\hline Agree & $59,6 \%$ & $53,0 \%$ & $55,8 \%$ \\
\hline Strongly agree & $28,6 \%$ & $33,7 \%$ & $31,5 \%$ \\
\hline $\begin{array}{l}\text { Assignments help me prepare for job } \\
\text { interviews }\end{array}$ & $U C$ & $U D A$ & Overall \\
\hline Strongly disagree & $12,1 \%$ & $6,6 \%$ & $9,0 \%$ \\
\hline Disagree & $37,7 \%$ & $14,4 \%$ & $24,5 \%$ \\
\hline Agree & $39,9 \%$ & $50,1 \%$ & $45,7 \%$ \\
\hline Strongly agree & $10,2 \%$ & $29,0 \%$ & $20,9 \%$ \\
\hline $\begin{array}{l}\text { Assignments help me become a better } \\
\text { professional }\end{array}$ & $U C$ & $U D A$ & Overall \\
\hline Strongly disagree & $10,2 \%$ & $4,3 \%$ & $6,9 \%$ \\
\hline Disagree & $21,6 \%$ & $5,5 \%$ & $12,5 \%$ \\
\hline Agree & $50,1 \%$ & $40,0 \%$ & $44,4 \%$ \\
\hline Strongly agree & $18,1 \%$ & $50,1 \%$ & $36,2 \%$ \\
\hline $\begin{array}{l}\text { Assignments help me become a better } \\
\text { person }\end{array}$ & $U C$ & $U D A$ & Overall \\
\hline Strongly disagree & $7,5 \%$ & $7,4 \%$ & $7,5 \%$ \\
\hline Disagree & $18,6 \%$ & $11,3 \%$ & $14,5 \%$ \\
\hline Agree & $58,8 \%$ & $42,5 \%$ & $49,5 \%$ \\
\hline Strongly agree & $18,1 \%$ & $50,1 \%$ & $36,2 \%$ \\
\hline $\begin{array}{l}\text { I do not see the benefit of completing } \\
\text { my reading assignments }\end{array}$ & $U C$ & $U D A$ & Overall \\
\hline Strongly disagree & $30,2 \%$ & $35,1 \%$ & $33,0 \%$ \\
\hline Disagree & $43,7 \%$ & $32,6 \%$ & $37,4 \%$ \\
\hline Agree & $20,2 \%$ & $22,6 \%$ & $21,6 \%$ \\
\hline Strongly agree & $5,9 \%$ & $9,7 \%$ & $8,0 \%$ \\
\hline
\end{tabular}

Of great importance to educators were the outcomes of the final group of statements that looked at how the university and professors could be of assistance to students in improving their reading compliance behaviors. Only a small majority of the respondents $(58,2 \%)$ felt that they needed help in 
figuring out how to improve their reading behavior. Yet, when quizzed further about where they would look for help it was interesting to find that professors, the content experts, were lowest on their list of priorities. As Table 6 shows, students would rather go to a student help center (62,3\%), their family $(59 \%)$, their friends $(51,6 \%)$ and other students $(48,6 \%)$ before they would contact their professors. Only $35 \%$ of the respondents stated they were likely to some extent to contact their professors, a sobering observation.

Finally, in this age of electronics, the survey also asked the respondents how the university could help them in completing their reading assignments. In the overall sample, $70 \%$ of the respondents felt that an e-mail reminder would help and $63,6 \%$ agreed that a text message would be beneficial. The most popular, however, was a reminder by their professors: $80,3 \%$ agreed that this would help them in completing their reading assignments.

Table 6. Sources students choose to help them improve their reading behavior.

\begin{tabular}{lrrr}
\hline Other students & UC & UDA & Overall \\
\hline Not at all & $14,3 \%$ & $13,6 \%$ & $13,9 \%$ \\
Very little & $37,5 \%$ & $37,6 \%$ & $37,5 \%$ \\
Somewhat & $36,4 \%$ & $37,2 \%$ & $36,8 \%$ \\
To a great extent & $11,9 \%$ & $11,7 \%$ & $11,8 \%$ \\
\hline My professors & UC & UDA & Overall \\
\hline Not at all & $24,8 \%$ & $35,3 \%$ & $30,8 \%$ \\
Very little & $39,1 \%$ & $30,6 \%$ & $34,3 \%$ \\
Somewhat & $27,8 \%$ & $23,2 \%$ & $25,2 \%$ \\
To a great extent & $8,4 \%$ & $10,9 \%$ & $9,8 \%$ \\
\hline Student assistance center & $U C$ & $U D A$ & Overall \\
\hline Not at all & $7,0 \%$ & $9,7 \%$ & $8,5 \%$ \\
Very little & $28,0 \%$ & $30,0 \%$ & $37,6 \%$ \\
Somewhat & $39,6 \%$ & $35,7 \%$ & $37,4 \%$ \\
To a great extent & $25,3 \%$ & $24,6 \%$ & $24,9 \%$ \\
\hline My friends & $U C$ & $U D A$ & Overall \\
\hline Not at all & $15,6 \%$ & $18,5 \%$ & $17,2 \%$ \\
Very little & $30,5 \%$ & $31,6 \%$ & $31,1 \%$ \\
Somewhat & $34,8 \%$ & $34,5 \%$ & $34,6 \%$ \\
To a great extent & $19,1 \%$ & $15,4 \%$ & $17,0 \%$ \\
\hline My family & $U C$ & $U D A$ & Overall \\
\hline Not at all & $8,9 \%$ & $16,2 \%$ & $13,1 \%$ \\
Very little & $27,0 \%$ & $28,7 \%$ & $27,9 \%$ \\
Somewhat & $32,9 \%$ & $29,6 \%$ & $31,0 \%$ \\
To a great extent & $31,3 \%$ & $25,5 \%$ & $28,0 \%$ \\
\hline
\end{tabular}

\subsection{Comparative results}

In order to determine if any of the observed differences of opinion in the tables were significant, $\mathrm{T}$ tests were used to compare the respondent groups in the sample. The groups compared were private university (UDA) vs. public university (UC), males vs. females and younger vs. older students. T-tests were appropriate because the groups were compared based on the value of a single variable and the level of data provided by the Likert scales was ordinal. In all instances, the null hypotheses assumed that the population means were equal and the alpha level was set at 0,05 , common in social science research.

\section{The effect of university origin on perceptions}

The study first looked at whether the university origin of the respondents had any significant effect on their reading behaviors and their perceptions about reading compliance. The study found numerous significant differences of opinion between UDA and UC students. In all the listed cases in this and the other two analyses, the null hypothesis of equality of mean ratings could be rejected, meaning that the observed differences of opinion were not the result of chance. A first look at Table 7, which 
summarizes the results, not only shows that there were many significant differences, but also that the significances were mostly at the 0,000 or 0,00 levels and therefore considerable (see Table 7).

The first and most important finding was that students at UC read significantly more than students at UDA and that the standard deviation for UC was considerably higher as well. The latter is an indication of the dispersion of answers in the sample. It was therefore not surprising that UC students also felt significantly more strongly that they got too many reading assignments and that they were too long. Yet, surprisingly perhaps, UDA students felt significantly more strongly that their reading assignments took a lot of time and that they did not have enough time to read the assignments.

Other interesting findings were that UDA students felt stronger about the value of reading assignments in providing them with a different perspective than their professor and that they were helpful in preparing for interviews, being a better professional and a better person. Finally, whereas UDA students were significantly more adamant about the fact that they could use help in figuring out their assignments, UC students were more likely to ask their family for help to complete their readings (see Table 7).

Table 7. Effect of university origin on perceptions.

\begin{tabular}{|c|c|c|c|c|c|}
\hline Questions & & $N^{*}$ & Mean & $S D$ & Sig. \\
\hline \multirow{2}{*}{ The time spent on reading assignment during the week } & $\mathrm{UC}$ & 371 & 7,53 & 7,49 & \multirow{2}{*}{$0,000 * * *$} \\
\hline & UDA & 487 & 4,64 & 5,50 & \\
\hline \multirow{2}{*}{ I get too many reading assignments } & $\mathrm{UC}$ & 371 & 2,79 & 0,79 & \multirow{2}{*}{$0,000 * * *$} \\
\hline & UDA & 487 & 2,41 & 0,86 & \\
\hline \multirow{2}{*}{ My reading assignments are too long } & $\mathrm{UC}$ & 371 & 2,78 & 0,82 & \multirow{2}{*}{$0,000 * * *$} \\
\hline & UDA & 487 & 2,41 & 1,54 & \\
\hline \multirow{2}{*}{ My reading assignments take a lot of time } & $\mathrm{UC}$ & 371 & 2,29 & 0,77 & \multirow{2}{*}{$0,000 * * *$} \\
\hline & UDA & 487 & 2,62 & 0,81 & \\
\hline \multirow{2}{*}{ I do not have enough time to read my assignments } & UC & 371 & 2,53 & 0,77 & \multirow{2}{*}{$0,000 * * *$} \\
\hline & UDA & 487 & 2,75 & 0,95 & \\
\hline \multirow{2}{*}{ My books are too expensive } & $\mathrm{UC}$ & 371 & 2,67 & 1,07 & \multirow{2}{*}{$0,000 * * *$} \\
\hline & UDA & 487 & 3,03 & 1,07 & \\
\hline \multirow{2}{*}{ I am more likely to read when assignments are graded } & $\mathrm{UC}$ & 371 & 3,11 & 0,90 & \multirow{2}{*}{$0,006 * *$} \\
\hline & UDA & 487 & 2,93 & 0,98 & \\
\hline \multirow{2}{*}{ Reading assignments present different perspective } & $\mathrm{UC}$ & 371 & 2,99 & 0,89 & \multirow{2}{*}{$0,001 * * *$} \\
\hline & UDA & 487 & 2,79 & 0,88 & \\
\hline \multirow{2}{*}{ Reading assignments help prepare for interviews } & $\mathrm{UC}$ & 371 & 2,47 & 0,87 & \multirow{2}{*}{$0,000 * * *$} \\
\hline & UDA & 487 & 2,98 & 0,91 & \\
\hline \multirow{2}{*}{ Reading assignments make me better professional } & UC & 371 & 2,75 & 0,90 & \multirow{2}{*}{$0,000 * * *$} \\
\hline & UDA & 487 & 2,99 & 0,83 & \\
\hline \multirow{2}{*}{ Reading assignments make me a better person } & UC & 371 & 2,79 & 0,83 & \multirow{2}{*}{$0,000 * * *$} \\
\hline & UDA & 487 & 3,10 & 0,95 & \\
\hline \multirow{2}{*}{ I could use help figuring out my reading assignments } & $\mathrm{UC}$ & 371 & 1,96 & 1,10 & \multirow{2}{*}{$0,000 * * *$} \\
\hline & UDA & 487 & 2,96 & 0,89 & \\
\hline \multirow{2}{*}{ I will ask family for help to complete assignments } & $\mathrm{UC}$ & 371 & 2,83 & 1,02 & \multirow{2}{*}{$0,002 * *$} \\
\hline & UDA & 487 & 2,59 & 1,11 & \\
\hline
\end{tabular}

\subsection{The effect of gender on perceptions}

A second grouping of respondents was along gender lines to determine whether male and female students had significant differences of opinion. It was found that there were very few significant differences of opinion between males and females. Females felt significantly stronger about the importance of their reading assignments being up-to-date and that reminders by professors helped them in finishing their assignments. Males, on the other hand, were significantly more likely to ask their family for help in finishing their assignments (see Table 8). 
Table 8. Effect of gender on perceptions.

\begin{tabular}{|c|c|c|c|c|c|}
\hline Questions & $\operatorname{Sex}$ & $N$ & Mean & $S D$ & Sig. \\
\hline \multirow{2}{*}{ My reading assignments are up-to-date } & $\mathrm{M}$ & 242 & 2,79 & 0,90 & \multirow{2}{*}{$0,009 * *$} \\
\hline & $\mathrm{F}$ & 614 & 2,96 & 0,82 & \\
\hline \multirow{2}{*}{ I will ask family for help in completing my assignments } & M & 242 & 2,85 & 1,04 & \multirow{2}{*}{$0,012 *$} \\
\hline & $\mathrm{F}$ & 614 & 2,64 & 1,10 & \\
\hline \multirow{2}{*}{ Reminders by professors help me finish assignments } & M & 242 & 2,85 & 1,01 & \multirow{2}{*}{$0,037 *$} \\
\hline & F & 614 & 3,01 & 1,08 & \\
\hline
\end{tabular}

\subsection{The effect of age on perceptions}

Finally, the study looked at the effect of age on reading behaviors and perceptions. Here the most interesting findings were that younger students $(<=20)$ thought their reading assignments took a lot of time and that they did not have enough time to read. They also felt significantly more strongly that reading assignments helped them in understanding the course content, in interviews and in being a better professional and a better person. They expressed a stronger need for help in figuring out their assignments and were significantly more appreciative of e-mail reminders as a way to help them comply with their reading assignments (see Table 9).

Table 9. Effect of age on perceptions.

\begin{tabular}{|c|c|c|c|c|c|}
\hline Questions & & $N^{*}$ & Mean & $S D$ & Sig. \\
\hline \multirow{2}{*}{ My reading assignments take a lot of time } & $<=20$ & 434 & 2,57 & 0,77 & \multirow{2}{*}{$0,000 * * *$} \\
\hline & $>20$ & 423 & 2,38 & 0,84 & \\
\hline \multirow{2}{*}{ I do not have enough time to read my assignments } & $<=20$ & 434 & 2,75 & 0,88 & \multirow{2}{*}{$0,002 * *$} \\
\hline & $>20$ & 423 & 2,56 & 0,88 & \\
\hline \multirow{2}{*}{ I do not buy books because they are too expensive } & $<=20$ & 434 & 3,00 & 1,04 & \multirow{2}{*}{$0,000 * * *$} \\
\hline & $>20$ & 423 & 2,74 & 1,12 & \\
\hline \multirow[b]{2}{*}{ My reading assignments help me understand content } & $<=20$ & 434 & 3,17 & 0,78 & \multirow{2}{*}{$0,046^{*}$} \\
\hline & $>20$ & 423 & 3,06 & 0,85 & \\
\hline \multirow{2}{*}{ My reading assignments help me for interviews } & $<=20$ & 434 & 2,83 & 0,90 & \multirow{2}{*}{$0,024 *$} \\
\hline & $>20$ & 423 & 2,69 & 0,96 & \\
\hline \multirow{2}{*}{ My reading assignments make me a better professional } & $<=20$ & 434 & 3,21 & 0,86 & \multirow{2}{*}{$0,000 * * *$} \\
\hline & $>20$ & 423 & 2,97 & 0,94 & \\
\hline \multirow{2}{*}{ My reading assignments make me a better person } & $<=20$ & 434 & 3,05 & 0,86 & \multirow{2}{*}{$0,010^{* *}$} \\
\hline & $>20$ & 423 & 2,89 & 0,97 & \\
\hline \multirow{2}{*}{ I could use help figuring out my reading assignments } & $<=20$ & 434 & 2,68 & 1,04 & \multirow{2}{*}{$0,006^{* *}$} \\
\hline & $>20$ & 423 & 2,47 & 1,14 & \\
\hline \multirow{2}{*}{ I will ask family for help to complete assignments } & $<=20$ & 434 & 2,62 & 1,03 & \multirow{2}{*}{$0,035 *$} \\
\hline & $>20$ & 423 & 2,78 & 1,12 & \\
\hline \multirow{2}{*}{ E-mail reminders help me complete assignments } & $<=20$ & 434 & 2,82 & 0,99 & \multirow{2}{*}{$0,045^{*}$} \\
\hline & $>20$ & 423 & 2,68 & 1,08 & \\
\hline
\end{tabular}

\section{DISCUSSION OF RESULTS}

A closer look at the results as summarized in the tables generates some interesting insights that can be food for thought for both professors and students and that can serve as starting points for future research endeavors. Based on a robust sample of 858 students at the University of Azuay and the University of Cuenca, the study found that students in both universities do not read much: an average of less than 6 hours a week spent on course assignments pales in comparison to reading behaviors of 
students at universities abroad. Yet, despite this low number, a large majority of the students indicated that they completed their reading assignments most of the time. In general, students did not feel overburdened by their reading assignments and were quite positive about the nature of their assignments: they felt they were interesting, up-to-date and enjoyable to read.

When asked why they did not complete their reading assignments it became clear that students did not read them primarily because they were not discussed in class and their tests were not based on their assignments. Secondary reasons were that they did not buy expensive books and that professors at times covered them completely in class, taking away their reasons for reading them. Clearly, the respondents stated that if there was no feedback or clear connection between reading assignments and the classroom, they were not motivated to read.

What caused students to read was if there was a clear connection between reading performance and their grades, if they were tested on the readings or called upon in class. As stated earlier, these are negative reinforcements yet they are effective in the eyes of the students, and once again, examples of clear connections between readings and course performance that make them read.

The most important results are summarized in Table 5 "Student Opinions about their Reading Assignments". Although there were some pockets of dissent, students generally showed themselves to be aware of the value and importance of their reading assignments. Large majorities agreed that reading assignments were helpful in their class work and in obtaining better grades. They stated that readings helped them in becoming better professionals and better persons and that they were important in understanding course content and for classroom discussions. Less than $30 \%$ of the respondents stated they did not see the benefits of completing their readings.

A small majority of the respondents expressed they needed help in improving their compliance behaviors. If they needed help with their reading assignments, students were more likely to ask family, friends, a student help center or fellow students than their professors, the content experts. Yet, by far the most popular way they chose to be reminded of their assignments was in class, by their professors.

By means of various T-tests, the study investigated if any of the observed differences of opinion were significant, using age, gender and university origin as distinguishing variables. There were many significant differences of opinion between students from the University of Cuenca and the University of Azuay. It was interesting to find that students at the UC read significantly more than the students at UDA which then also lead to significant difference in statements that examined perceptions about number and length of the assignments. Yet, despite the fact that they read significantly less, UDA students were significantly more appreciative of the value of the readings with regard to their personal and professional development. UDA students needed significantly more help with their assignments whereas UC students turned to their families significantly more often when it came to completing their assignments.

The study found few significant differences of opinion between males and females, yet age once again had a considerable impact on opinions. Younger students were significantly more pressed for time as compared to their older peers, yet also felt stronger about the value of their reading assignments. As was to be expected, they needed significantly more help figuring out and completing their assignments.

\section{CONCLUSION}

So where does this leave us? Anecdotal evidence from foreign universities suggests that Ecuadorian students do not read much in preparation for their classes in comparison to their peers abroad. One can make various assumptions as to why that might be the case. It could be that they are not accustomed to reading in general and have never done so. Recent data from the Ecuadorian Instituto Nacional de Estadisticas y Censos (National Census Bureau) suggest that only 50,3\% of Ecuadorians dedicate 1 to 2 hours per week to reading (El Mecurio, 2013). It could be that they truly do not have time to read because they have so many class contact hours: when students are in class for 25-30 hours per week, with many of them working afterwards, there may indeed not be enough time for them to read all of 
their assignments. Another potential explanation might be that students are not asked or required to read in preparation for class because their professors do not assign them many readings. And that, in turn, might perhaps be related to the reading habits and behaviors of the professors themselves.

This study found that students do not feel overburdened by their reading assignments and that they see their value, both in terms of class preparation and in terms of larger, personal and professional development. For the most part, they felt their readings were interesting and up-to-date. A large majority of them considered them important to course content, class discussion and their grades.

A third message the students conveyed was that they needed to be stimulated to read, either positively or negatively. Negative stimulants they mentioned were lower grades, being called upon in class or being tested. Positive stimulants identified were reinforcement in classroom discussion and a stronger connection between the readings and the classroom.

Efforts to improve student reading behavior need to start with the professors: with students seeing the value and relevance of their readings there is room for professors to assign more readings (or any readings in case there are none) as part of their course requirements. If they provide better connectivity between course performance and reading assignments and if they follow up reading assignments with class discussions, students will read more. Students reading more will mean more time in class to discuss and teach higher level content. And that, in turn, will raise the educational bar for all.

As the literature on the topic suggests, Ecuadorian professors could consider using surprise quizzes, open-ended rather than multiple choice questions, graded reading assignments and online discussions to stimulate student reading compliance. Class discussions of readings stimulate compliance as well, yet only if they are summaries and used to present additional material. When class discussion repeats course readings word-for-word, students are inclined not to read their assignments. Finally, as the respondents indicated regular reminders of reading assignments in class and by e-mail also encourage them to read. Yet, for that to function well a culture of reading e-mails from professors needs to be prevalent among students.

To our knowledge, research on the topic of student reading behaviors and compliance has not been done in the South American setting. This article therefore not only hoped to make a small contribution to the existing body of knowledge in presenting a different cultural perspective, but also in corroborating some of the findings of research in other cultures and other academic environments. Based on these and other findings, there are numerous avenues for future research. The differences this study found in reading behaviors and perceptions of students in private and public universities could be investigated more in depth. A second possibility for future research is to look at crosscultural differences and compare reading behaviors of students in other cultures/countries to those observed here. Finally, an interesting opportunity for future investigation lies in a study of the reading behaviors of professors that addresses such issues as how much they read, what they read, whether they read in Spanish and/or English, if they read literature in their fields of research interest, how much they expect their students to read as part of their course requirements and what their level of agreement is with the findings of this study.

Ecuador's system of higher education is undergoing major and dramatic changes, intended to raise the level of teaching and research. Many in the system struggle with these changes and feel out of control because they are imposed from the outside. However, changing students' reading behavior starts from the inside. As teaching loads for professors are reduced from twenty-four (or more) hours to sixteen-hours per week there will be more time for research, course preparation and quality improvement initiatives. Professors can and should expect more of their students as more is expected of them as well and they should teach to higher standards. As quality slowly takes over from quantity, improving student reading behavior is a small, yet important, step in improving the level of higher education, not only for students but for professors as well. 


\section{REFERENCES}

Baier, K., C. Hendricks, K.W. Gorden, J.E. Hendricks, L. Cochran, 2011. College students' textbook reading, or not! American Reading Forum Annual Yearbook 31.

Burchfield, C.M., J. Sappington, 2000.Compliance with required reading assignments. Teach. Psychol., 27(1), 58-60.

Clump, M.A., H.Bauer, C. Bradley, 2004. The extent to which psychology students read textbooks: A multiple class analysis of reading across the psychology curriculum. J. Instr. Psychol., 31(3), 227-232.

Clump, M.A., J. Doll, 2007. Do levels of reading course material continue? An examination in a forensic psychology graduate program. J. Instr. Psychol., 34(4), 242-246.

Connor-Greene, P.A., 2000. Assessing and promoting student learning: Blurring the line between teaching and testing. Teach. Psychol., 27, 84-88.

Coulter, C.J., S. Smith, 2012. The impact of preclass reading assignments on class performance. Currents Pharm. Teach. Learn., 4(2), 109-112.

El Mercurio, April 23, 2013. Tiempo dedicado a lectura es baja.

Fujita, K., Y. Trope, N. Liberman, M. Levin-Sagi, 2006. Construal levels and self-control. J. Pers. Soc. Psychol., 90, 351-367.

Gurung, R.A.R., R.C. Martin, 2011. Predicting textbook reading: The textbook assessment and usage scale. Teach. Psychol., 38(1), 22-28.

Hobson, E., 2004. Getting students to read: Fourteen tips. IDEA Paper. No. 40, http://www.idea.ksu.edu (under "Idea Papers" in left column).

Johnson, B.C., M.T. Kiviniemi, 2009. The effect of online chapter quizzes on exam performance in an undergraduate social psychology course. Teach. Psychol., 36(1), 33-37.

Kouyoumdjian, H., 2004. Influence of unannounced quizzes and cumulative exam on attendance and study behavior. Teach. Psychol., 31(2), 110-111.

Lei, S.A., K.A. Bartlett, S.E. Gorney, T.R. Herschbach, 2010. Resistance to reading compliance among college students: Instructors' perspectives. J. Coll. Student, 44(2), 219-229.

Lineweaver, T.T., 2010. Online discussion assignments improve students' class preparation. Teach. Psychol., 37(3), 204-209.

Marek, P., A.N. Christopher, 2011. What happened to the first "R"?: Students' perceptions of the role of textbooks in psychology courses. Teach. Psychol., 38(4), 237-242.

McMinn, M.R., A. Tabor, B.L. Trihub, L. Taylor, A.W. Dominquez, 2009. Reading in graduate school: A survey of doctoral students in clinical psychology. Train.Educ. Prof. Psychol., 3(4), 233-239.

Sappington, J., K. Kinsey, K. Munsayac, 2002. Two studies of reading compliance among college students. Teach. Psychol., 29(4), 272-274.

Schaefer, D.R., D.A. Dillman, 1998. Development of standard e-mail methodology: Results of an experiment. Public Opin. Quart., 62(3), 378-397.

Tse, A.C., 1998. Comparing the response rate, speed and response quality of two methods of sending questionnaires: E-mail vs. mail. J. Market Res. Soc., 40(4), 353-361.

Uskul, A.K., J. Eaton, 2005. Using graded questions to increase timely reading of assigned material. Teach. Psychol., 38(4), 116-118.

Wertenbroch, K., 2002. Hedonic interactions between choice and consumption. Adv. Consum. Res., 29, 105-107. 